\title{
A cross-sectional approach including dog owner characteristics as predictors of visceral leishmaniasis infection in dogs
}

\author{
Ana Izabel Passarella Teixeira1', Debora Marcolino Silva', Lúcia Rolim Santana de Freitas², Gustavo \\ Adolfo Sierra Romero ${ }^{1 /+}$
}

${ }^{1}$ Universidade de Brasília, Faculdade de Medicina, Núcleo de Medicina Tropical, Brasília, DF, Brasil

${ }^{2}$ Ministério da Saúde, Secretaria de Vigilância Epidemiológica, Brasília, DF, Brasil

BACKGROUND Visceral leishmaniasis (VL) is relevant for human and animal public health. Several factors have been associated with the risk of Leishmania infantum infection in dogs. However, dog owner characteristics have been rarely explored.

OBJECTIVES To estimate the prevalence and to identify the associated factors for VL infection including dog owners characteristics.

METHODS A cross-sectional study was conducted including dogs from an endemic canine visceral leishmaniasis (CVL) region in the Federal District, Brazil. The infection was detected using parasitological, serological, and molecular methods. The associated factors were identified through Poisson regression modelling.

FINDINGS The prevalence of infection was $26.25 \%$ [95\% confidence interval (CI): 20.05 to 33.57$]$. The associated factors were: short coat prevalence ratio $(\mathrm{PR})=2.33(95 \% \mathrm{CI}: 1.02$ to 5.22); presence of backyard with predominance of soil and/or vegetation $\mathrm{PR}=4.15$ (95\% CI: 1.35 to 12.77$)$; and highest gross family income score $\mathrm{PR}=2.03$ (95\% CI: 1.16 to 3.54$)$.

MAIN CONCLUSION This is the first study that relates higher socioeconomic status of dog owners as an independent factor associated with higher prevalence of VL infection, along with other strongly associated factors related to receptive environment for phlebotomines. Our findings strengthen the need for exploration of the biological and behavioural bases linking dog owner characteristics to the risk of canine infection in prospective cohort studies.

Key words: canine visceral leishmaniasis - risk factors - prevalence - cross-sectional study - serology

American visceral leishmaniasis (VL) is a zoonotic disease associated with infection by Leishmania infantum, a parasite transmitted by the bite of phlebotomine females, especially Lutzomyia longipalpis..$^{(1)}$ Human visceral leishmaniasis (HVL) is a prominent public health problem worldwide. ${ }^{(2)}$ In Brazil, the disease burden has been estimated as 20.9 (UI: $95 \%, 11.3$ to 34.8 ) age-standardised disability-adjusted life years (DALYs) rate per 100.000 inhabitants..$^{(3)}$ In 2014, the total cost of VL was estimated as 15 million US dollars, including direct medical costs related to diagnostic, treatment and care provided to patients and indirect costs through productivity loss due to premature mortality and morbidity. ${ }^{(4)}$

Dogs are considered the main source of infection in urban areas and this represents a major challenge for the implementation of control measures, resulting in the euthanasia of seropositive animals in an attempt to reduce the risk of transmission to humans. ${ }^{(5)}$ However, euthanasia has been increasingly rejected due to the appreciation of pets, especially dogs. ${ }^{(6,7)}$ In addition, its ineffectiveness has raised concerns. ${ }^{(8)}$

doi: 10.1590/0074-02760190349

Financial support: FAPDF (process 193.000.867/2015), CNPq (process 142247/2015-4)

+ Corresponding author: gromero@unb.br

(1) https://orcid.org/0000-0003-1425-926X

Received 14 September 2019

Accepted 11 February 2020
Because of these difficulties, new preventive and therapeutic measures have been developed and applied in recent years, such as the use of anti-ectoparasite products, repellents and even the treatment of the disease in animals. Although these measures, directly or indirectly, reduce the risk of acquiring the infection or improve the prognosis for the development of symptomatic canine visceral leishmaniasis (CVL), further studies are needed to identify their possible impacts on human health..$^{(9,10,11)}$ For these reasons, it is important to study the factors that may be involved in the disease process, improving its understanding, which may contribute to better strategies for disease control.

Indeed, several studies investigated the factors, especially biological characteristics of dogs, associated with the risk of developing CVL. A short coat, for example, stands out as the most relevant factor. ${ }^{(12,13,14)}$ However, there are multiple other potential factors that have not been explored yet.

These include (i) the owner's knowledge and awareness of VL, both in humans and $\operatorname{dogs},{ }^{(15,16)}$ (ii) the availability of adequate sanitary systems, such as sewage, treated water and garbage collection, ${ }^{(13,17)}$ (iii) the presence of organic matter, either in the yard or in some proximity, ${ }^{(18)}$ and (iv) the existence of highways and the movement of people and animals. ${ }^{(19)}$ It should be emphasised that all of these studies demonstrate that human action on the environment is closely related to the development of the disease.

To ascertain human action in the occurrence of CVL, we evaluated the prevalence of CVL in an endemic region in the Federal District and explored the association of several risk factors for infection, including the less studied risk factors which are related to the socioeconomic status of the dog owners and the care provided to the animals. 


\section{MATERIALS AND METHODS}

Type of study - Cross-sectional descriptive and analytical study.

Period of study - The study was conducted from October 2015 to March 2017.

Location of study - Data collection was performed in the XXXI administrative region of the Federal District, named Fercal. This location is endemic for human and canine cases of VL ${ }^{(20,21)}$ (Fig. 1).

Participants of the study - The dog owners participated in the study by completing a questionnaire for the assessment of their socio-economic status and the care they provide to their dogs. The dogs included in the study were physically examined. In addition, blood, bone marrow, or both were collected from the animals for diagnostic tests

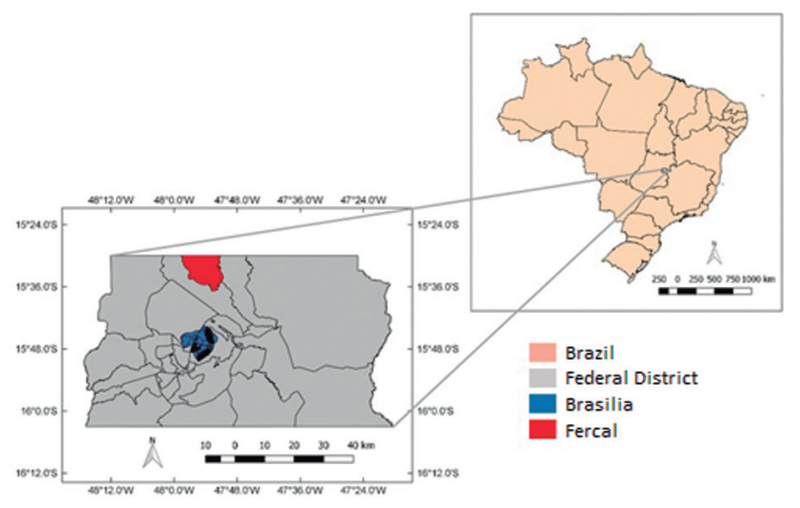

Fig. 1: geographical location of the Fercal Administrative Region in Federal District, Brazil.
Eligibility criteria - The eligibility criteria were applied by residence and the unit of analysis was the dog. Thus, the residence was eligible when owner's and dogs' eligibility criteria were met. The owner's criteria were being older than 18 years old and willingness to read and sign the Informed Consent Form. The dogs' criterion was being older than four months. Animals with behaviour or health problems that precluded the application of diagnostic procedures under mild sedation, such as severe heart disease, seizures and extreme aggression, were excluded.

Sample size - The canine population in the Fercal administrative region was estimated based on the human population of 8746 inhabitants, which was estimated from a sample survey conducted in 2013. ${ }^{(22)}$ It was assumed that every household was composed of five inhabitants. Because no official data of dog population was available at that time, we performed preliminary non-systematic observations in the study field and presumed that $20 \%$ of the households would have a dog, resulting in the estimated population of $342 \mathrm{dogs}$.

Based on previous studies in which the seroprevalence for CVL in Fercal ranged from 7 to $14 \%,{ }^{(9,22)}$ the expected frequency of canine infection was estimated as $10 \%$. Considering a margin of error of 5\% and a confidence interval (CI) of $95 \%$, and accounting for a possible conglomerate effect (a residence may have more than one dog), a correction in the design effect of 1.5 was included in the calculation. ${ }^{(23)}$ Losses of $10 \%$ were also estimated resulting in a final sample size of 160 animals. Samples were calculated using the Stat Calc program from Epi Info, version 7.2.0.1.

Sampling - The data collection was performed in a systematic manner starting with the residence in Fercal closest to the Plano Piloto of the Federal District; data

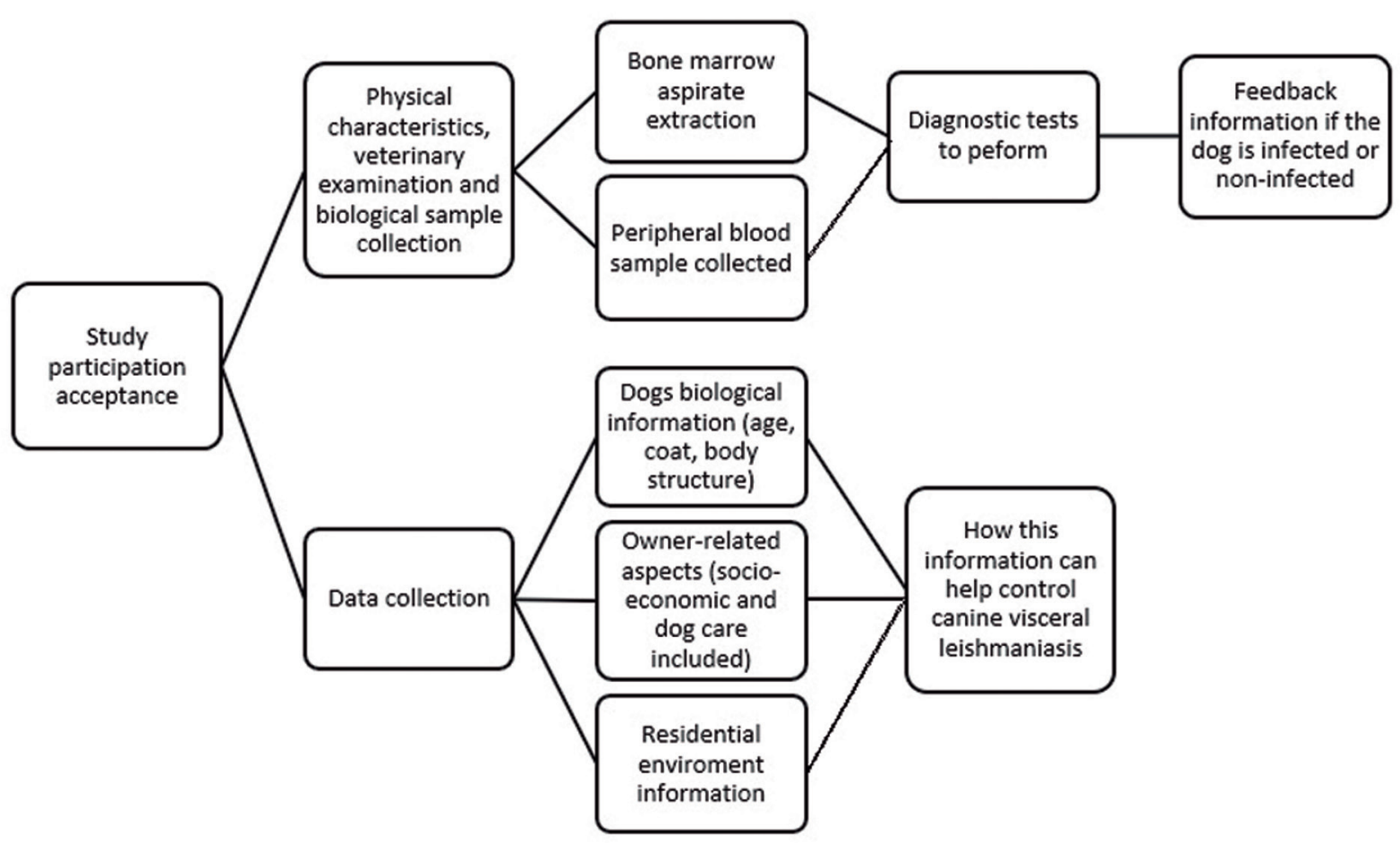

Fig. 2: study stages flowchart as presented to the owners. 
TABLE I

Relationship between economic class and mean gross family income ${ }^{(24)}$

\begin{tabular}{lcc}
\hline Class & Points & $\begin{array}{c}\text { Mean gross family income in Bra- } \\
\text { zilian Reais (BRL) }\end{array}$ \\
\hline A1 & $42-46$ & 11,037 \\
\hline A2 & $35-41$ & 6,006 \\
\hline B1 & $29-34$ & 3,118 \\
\hline B2 & $23-28$ & 1,865 \\
\hline C1 & $18-22$ & 1,277 \\
\hline C2 & $14-17$ & 895 \\
\hline D & $8-13$ & 895 \\
\hline E & $0-7$ & 895 \\
\hline
\end{tabular}

were collected from only one house from each block. In cases where the residence approached first was not eligible, the team would visit the next house, and so on, until an eligible residence was found. After the data collection was completed at an eligible residence, the team continued the process in the next block. There were blocks in which no animals were found and blocks in which none of the owners agreed to participate in the study. Accordingly, no data was collected from such blocks. All blocks were covered by the collection team so that the entire Fercal territory was represented in the sampling [Supplementary data (Fig. 1)].

Data collection - After verifying compliance with the eligibility criteria, the team presented the study to the owners and provided details on the process and data collection (Fig. 2). After being informed that positive results for leishmaniasis would be reported to the Diretoria de Vigilância Ambiental do Distrito Federal (Environmental Surveillance Board of the Federal District; DIVAL-DF) for the implementation of the adequate control measures, the owners read and signed the informed consent form.

The owners filled out a questionnaire about several aspects of their residence and the care provided to the dogs. Also, a series of questions were asked to estimate their socioeconomic status, according to recommendations by the Associação Brasileira de Empresas de Pesquisa (Brazilian Association of Research Companies; ABEP) ${ }^{(24)}$ (Table I).

The data including the physical characteristics and clinical data of the dogs were recorded. The dogs were categorised as asymptomatic or symptomatic according to the LeishVet Guidelines. ${ }^{(25)}$ Clinical data were recorded without knowledge of the infection diagnosis, and a score of signs was assigned to each dog following a model adapted from Proverbio et al.(26) This adaptation consisted of eliminating items that could not be determined by a single physical examination. The excluded items were change in appetite, change in mental state, exercise intolerance, weight loss, polyuria, polydipsia and proteinuria. These items, if present at their highest intensity, could add up to 20 points to the score.
Because there was more than one veterinarian performing biological sample collection and physical examination, other items that could be subjectively evaluated were modified so that only the presence or absence of these signs was reported. These items were skin lesions, hepatosplenomegaly, epistaxis, vomiting, diarrhea, claudication, altered pigmentation, hyperkeratosis and onychogryphosis. With this modification, these items could add 21 points if each factor was rated as maximum intensity. The modified clinical score was validated in the field through a pilot study in which 20 evaluations were performed by two veterinarians. The final evaluation applied in the study had a maximum score of 46 points, instead of 87 as in the original evaluation according to Teixeira et al. ${ }^{(27)}$

Collection, transport, and storage of biological samples - Peripheral blood (cephalic vein, saphenous vein or jugular vein) was collected using a $3 \mathrm{~mL}$ syringe and a $25 \times 0.7 \mathrm{~mm}$ needle. The collected blood was stored in two tubes, one with EDTA anticoagulant for molecular tests and the other without anticoagulant to perform serological tests.

The samples were transported to the Leishmaniasis Laboratory of the Tropical Medicine Centre/University of Brasilia (NMT/UnB) under refrigeration, i.e. at $4-8^{\circ} \mathrm{C}$. Immediately after arrival at the laboratory, serum was separated by centrifugation at $1512 \times g$ for $3 \mathrm{~min}$. Whole blood and serum samples were stored at $-20^{\circ} \mathrm{C}$ until the serological or molecular tests were performed.

The collection of bone marrow aspirate from the sternum was performed under sedation. Sedation was performed with intramuscular injection of ketamine $(8 \mathrm{mg}$ per $\mathrm{kg}$ body weight) combined with acepromazine ( $0.1 \mathrm{mg}$ per $\mathrm{kg}$ body weight). After sedation, the animals were placed on a stainless-steel table for trichotomy and sequentially cleaned with soap and water, iodinated alcohol and 70\% alcohol. The collection was performed with a disposable syringe $(20 \mathrm{~mL})$ and a 40 -gauge needle $(1.2 \mathrm{~mm})$.

Definition of infection - A dog with positive results for any of the following diagnostic protocols was considered infected: direct parasitological examination; culture of the parasite; polymerase chain reaction (PCR) amplification of the ITS1 target; Dual-Path Platform rapid test (TR DPP) serology (Biomanguinhos $($ ) ) and ELISA serology (EIE-CVL) (Biomanguinhos $($ ), sequentially; and (RT DPP) (Biomanguinhos $\left.{ }^{\circledR}\right)$ serology and ELISA serology (rK39), sequentially. Dogs that presented negative results for all diagnostic protocols mentioned above were considered non-cases.

Diagnostic tests procedures - Direct parasitology; parasite culture; PCR amplification of the ITS1 target; RT DPP serology (Biomanguinhos ${ }^{\circledR}$ ) and ELISA serology (EIE-CVL) (Biomanguinhos $\AA$ ), sequentially; TR DPP serology (Biomanguinhos ${ }^{\circledR}$ ) and ELISA serology (Rk39), sequentially, were performed according to the methodology described in the study by Teixeira et al. ${ }^{(27)}$ When the tests were performed, the professionals were not aware of the identity of the source animals or of the results obtained for the other tests.

Data management - All missing data were appointed in the frequency and proportions analyses. Data were 


\section{TABLE II}

Absolute and relative frequencies of clinical signs observed in infected and uninfected dogs residing in the Fercal administrative region, Federal District, Brazil, 2015-2017

\begin{tabular}{|c|c|c|c|c|}
\hline Findings & & Infected & Non-infected & p-value \\
\hline \multirow{3}{*}{ Bodily condition } & Obese/Normal & $35 / 42(83.33 \%)$ & $99 / 116(85.34 \%)$ & 0.131 \\
\hline & Thin & $3 / 42(7.14 \%)$ & $14 / 116(12.06 \%)$ & \\
\hline & Cachectic & $4 / 42(9.53 \%)$ & $3 / 116(2.58 \%)$ & \\
\hline \multirow[t]{2}{*}{ Mucosal paleness } & None & $34 / 42(80.95 \%)$ & $98 / 116(84.48 \%)$ & 0.597 \\
\hline & Present & $8 / 42(19.05 \%)$ & $18 / 116(15.52 \%)$ & \\
\hline \multirow[t]{3}{*}{ Dehydration } & None & $40 / 42(95.24 \%)$ & $113 / 116(97.41 \%)$ & 0.926 \\
\hline & Mild & $1 / 42(2.38 \%)$ & $2 / 116(1.71 \%)$ & \\
\hline & Moderate to intense & $1 / 42(2.38 \%)$ & $1 / 116(0.85 \%)$ & \\
\hline \multirow[t]{2}{*}{ Mild muscle atrophy of the limbs } & None & $41 / 42(97.62 \%)$ & $115 / 116(99.14 \%)$ & 0.451 \\
\hline & Present & $1 / 42(2.38 \%)$ & $1 / 116(0.85 \%)$ & \\
\hline \multirow[t]{2}{*}{ Skin lesions } & None & $29 / 42(69.05 \%)$ & $80 / 118(68.96 \%)$ & 0.992 \\
\hline & Present & $13 / 42(30.96 \%)$ & $36 / 116(31.04 \%)$ & \\
\hline \multirow[t]{2}{*}{ Hepatosplenomegaly } & None & $35 / 40(87.50 \%)$ & $107 / 116(92.24 \%)$ & 0.366 \\
\hline & Present & $5 / 40(12.50 \%)$ & $9 / 116(7.76 \%)$ & \\
\hline \multirow{3}{*}{ Conjunctivitis and/or Keratitis } & None & $35 / 42(83.33 \%)$ & $107 / 116(92.24 \%)$ & 0.247 \\
\hline & Unilateral and mild & $2 / 42(4.76 \%)$ & $2 / 116(1.72 \%)$ & \\
\hline & Severe unilateral/bilateral & $5 / 42(11.90 \%)$ & $7 / 116(6.03 \%)$ & \\
\hline \multirow[t]{2}{*}{ Uveitis and/or Blepharitis } & None & $39 / 42$ & $110 / 115$ & 0.481 \\
\hline & Present & $3 / 42(7.14 \%)$ & $5 / 115(4.35 \%)$ & \\
\hline \multirow[t]{3}{*}{ Lymph adenomegaly } & None & $24 / 42(57.14 \%)$ & $73 / 116(62.93 \%)$ & 0.803 \\
\hline & 1 to 2 lymph nodes & $12 / 42(28.57 \%)$ & $29 / 116(25.0 \%)$ & \\
\hline & 3 or more / widespread & $6 / 42(14.28 \%)$ & $14 / 116(12.07 \%)$ & \\
\hline \multirow[t]{2}{*}{ Mouth ulcers or nodules } & None & $41 / 42(97.62 \%)$ & $116 / 116(100.0 \%)$ & 0.096 \\
\hline & Present & $1 / 42(2.38 \%)$ & $0 / 116(0 \%)$ & \\
\hline \multirow[t]{2}{*}{ Diarrhea } & None & $39 / 42(92.86 \%)$ & $111 / 116(95.69 \%)$ & 0.473 \\
\hline & Present & $3 / 42(7.14 \%)$ & $5 / 116(4.31 \%)$ & \\
\hline \multirow[t]{2}{*}{ Claudication } & None & $42 / 42(100.0 \%)$ & $115 / 116(99.14 \%)$ & 0.546 \\
\hline & Present & $0(0 \%)$ & $1 / 116(0.85 \%)$ & \\
\hline \multirow[t]{2}{*}{ Erythema (1 to $25 \%$ of the body surface) } & None & $42 / 42(100.00 \%)$ & $114 / 116(98.28 \%)$ & 0.392 \\
\hline & Present & $0(0 \%)$ & $2 / 116(1.72 \%)$ & \\
\hline \multirow{4}{*}{ Dry exfoliative dermatitis } & None & $32 / 42(76.19 \%)$ & $94 / 116(81.03 \%)$ & 0.739 \\
\hline & 1 to $25 \%$ of the body & $7 / 42(16.67 \%)$ & $13 / 116(11.21 \%)$ & \\
\hline & $>25$ to $40 \%$ of the body & $2 / 42(4.76 \%)$ & $4 / 116(3.44 \%)$ & \\
\hline & $>40 \%$ of the body & $1 / 42(2.38 \%)$ & $5 / 116(4.31 \%)$ & \\
\hline \multirow[t]{4}{*}{ Ulcerative dermatitis } & None & $38 / 42(90.48 \%)$ & $112 / 116(96.55 \%)$ & 0.306 \\
\hline & 1 to $25 \%$ of the body & $3 / 42(7.14 \%)$ & $3 / 116(2.58 \%)$ & \\
\hline & $>25 \%$ of the body & $1 / 42(2.38 \%)$ & $1 / 116(0.85 \%)$ & \\
\hline & - & - & - & \\
\hline \multirow[t]{2}{*}{ Nodular dermatitis } & None & $39 / 42(92.86 \%)$ & $114 / 116(99.24 \%)$ & 0.086 \\
\hline & Present & $3 / 42(7.14 \%)$ & $2 / 116(1.72 \%)$ & \\
\hline \multirow{2}{*}{ Pustular dermatitis } & None & $41 / 42(97.62 \%)$ & $115 / 116(99.24 \%)$ & 0.451 \\
\hline & Present & $1 / 42(2.38 \%)$ & $1 / 116(0,86 \%)$ & \\
\hline \multirow[t]{3}{*}{ Alopecia } & None & $36 / 42(85.71 \%)$ & $105 / 116(90.52 \%)$ & 0.766 \\
\hline & 1 to $25 \%$ of the body & $3 / 42(7.14 \%)$ & $8 / 116(6.89 \%)$ & \\
\hline & $>25 \%$ of the body & $3 / 42(7.14 \%)$ & $3 / 116(2.59 \%)$ & \\
\hline \multirow[t]{2}{*}{ Altered pigmentation } & None & $40 / 42(95.24 \%)$ & $111 / 116(95.69 \%)$ & 0.903 \\
\hline & Present & $2 / 42(4.76 \%)$ & $5 / 116(4.31 \%)$ & \\
\hline \multirow[t]{2}{*}{ Hyperkeratosis of truffles and cushions } & None & $39 / 42(92.86 \%)$ & $114 / 116(98.28 \%)$ & 0.086 \\
\hline & Present & $3 / 42(7.14 \%)$ & $2 / 116(1.72 \%)$ & \\
\hline \multirow[t]{2}{*}{ Onychogryphosis } & None & $38 / 42(90.48 \%)$ & $114 / 116(98.28 \%)$ & 0,023 \\
\hline & Present & $4 / 42(9.52 \%)$ & $2 / 116(1.72 \%)$ & \\
\hline
\end{tabular}


collected as reported by the owner. However, the data was verified where possible, for example through vaccination cards or visual examination. All data collected, including biological samples, were coded so that the analyses were conducted blindly.

Statistical analysis - Descriptive analyses of the data were performed, with calculations of disease/infection prevalence and $95 \%$ CI. Subsequently, the analytical phase was initiated with a bivariate analysis and respective prevalence ratio (PR), in which the significant variables with $p$-values less than or equal to 0.2 were selected for the multivariate analysis using Poisson regression.

For these analyses, the calculation of the quartile analysis of the clinical signs scores suggestive of CVL and of the family income score and its transformation into a categorical variable can be seen in Table II.

Poisson regression with robust variance was used to estimate PR and respective 95\% CI as measures of association. Modelling followed a hierarchical structure in which owner characteristics and care of the dogs were considered as proximal exposures, characteristics of the residential environment as an intermediate exposure, and biological factors as distal exposures.

Ethical considerations - All procedures were designed to reduce animal suffering. All owners were informed about the risks of the procedures and the risks of VL, both for the human and canine populations, and the owners had access to the results of the tests. The study was approved by the Ethics Committee on Animal Use of UnB under the number UnBDoc 11253/2015, in accordance with Law 11.794 of October 8, 2008. ${ }^{(28)}$

\section{RESULTS}

A total of 160 dogs belonging to 112 owners were included in the study (1.47 dogs per owner on average). Among the 112 owners, 76 (67.9\%) had one participating $\mathrm{dog}, 26$ (23.2\%) had two participating dogs, and $10(8.9 \%)$ had more than two participating dogs. There were 28 refusals; additionally, five dogs were excluded for having severe heart disease, and one dog was excluded for having been vaccinated against $\mathrm{VL}$. Of the questionnaires used to obtain data regarding owners, residences and care offered to dogs, 109 were considered valid, and three invalid.

The mean gross family income score was 17.45 points $(\mathrm{SD}=5.70)$. Most owners belonged to socioeconomic strata $\mathrm{C} 1$ and $\mathrm{C} 2$, with a mean gross family income of BRL 895.00 to BRL 1,277.00. The PR in each quartile was: 0.58 (95\% CI: 0.25 to 1.30$)$ for quartile $1,0.73(95 \%$ CI: 0.34 to 1.55$)$ for quartile 2, 1.47 (95\% CI: 0.95 to 2.27) for quartile 3 , and 1.08 ( $95 \%$ CI: 0.57 to 2.06 ) quartile 4. Of the $160 \mathrm{dogs}, 71(44.4 \%)$ were females, and 89 $(55.6 \%)$ were males. The mean age was 3.06 years (SD 2.86 years, range four months to 15 years).

Clinical signs data were available for $158 \mathrm{dogs}$, of which $53.79 \%$ (85/158) were asymptomatic (score less than or equal to 1 point) and $46.21 \%$ (73/158) were symptomatic (score greater than or equal to 2). The clinical score values for the infected dogs with onychogryphosis were $6,11,14$ and 26 . The clinical score values for the dogs without infection were 3 and 4 . The frequency of clinical signs observed in infected and noninfected dogs is described in Table II.

Bone marrow aspirate was collected from $62.5 \%$ $(100 / 160)$ of the dogs. Of those samples, $2 \%(2 / 100)$ were positive for isolation of the parasite in culture and $8 \%$ $(8 / 100)$ were positive by direct observation of the parasite.

Eighty-eight (55\%) of the 160 blood samples and 56 (56\%) out of the 100 bone marrow samples were positive for kDNA PCR. These positive samples were subjected to PCR for amplification of ITS1; 14/88 (15.90\%) of the whole blood samples and $13 / 56(23.21 \%)$ of the bone marrow samples were positive. Thus, 26/160 animals $(16.25 \%)$ were considered positive according to the parameters used to define infection using molecular diagnostic tests. Of these, 12 animals were positive only using bone marrow analysis, 13 animals were positive only using peripheral blood analysis, and one animal was positive using both of these.

Regarding the serological tests, 25/160 animals were positive by RT DPP (Biomanguinhos ${ }^{\circledR}$ ) and $24 / 160$ by EIE-CVL (Biomanguinhos $\left.{ }^{\circledR}\right)$. However, only $15(9.38 \%)$ animals were positive by both tests. In turn, when RT DPP (Biomanguinhos ${ }^{\circledR}$ ) and ELISA rk39 were used in combination, only $19(11.88 \%)$ animals were positive by both tests. Therefore, considering the criteria established in the methodology section for the definition of infection using serological methods, 42 infected dogs were identified.

The estimated prevalence of infected dogs was $26.25 \%$ (95\% CI: 20.05 to 33.57). Of the 42 infected dogs, only 22 presented a score of signs compatible with CVL greater than or equal to 2 and were considered symptomatic. Therefore, the prevalence of disease in the studied sample was $13.75 \%$ (95\% CI: 9.26 to 19.94$)$. There was no statistically significant difference in the median of the clinical score among infected and noninfected dogs (Fig. 3).

The estimated seroprevalence using sequential TR DPP/EIE-CVL testing was 15/160 (9.38\%) animals (95\% CI: 5.76 to 14.89 ). The estimated seroprevalence using

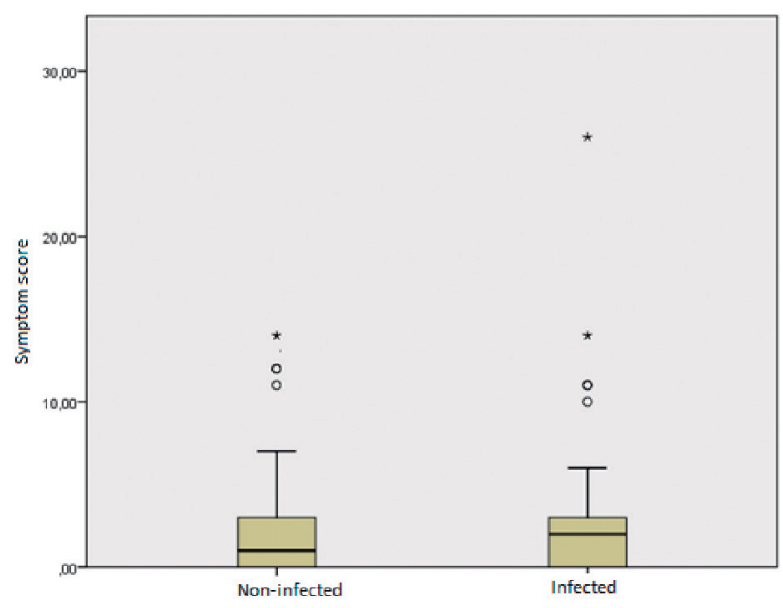

Fig. 3: distribution of the clinical canine visceral leishmaniasis score in the infected and uninfected animal groups, Brasília 2017. 118 uninfected dogs, median 1 (IQR: 0-3, range 0-14 points). 42 infected dogs, median 2; (IQR: 0-3, range 0-26 points). (Mann-Whitney $\mathrm{U}$ test; $\mathrm{p}=0.377$ ). 

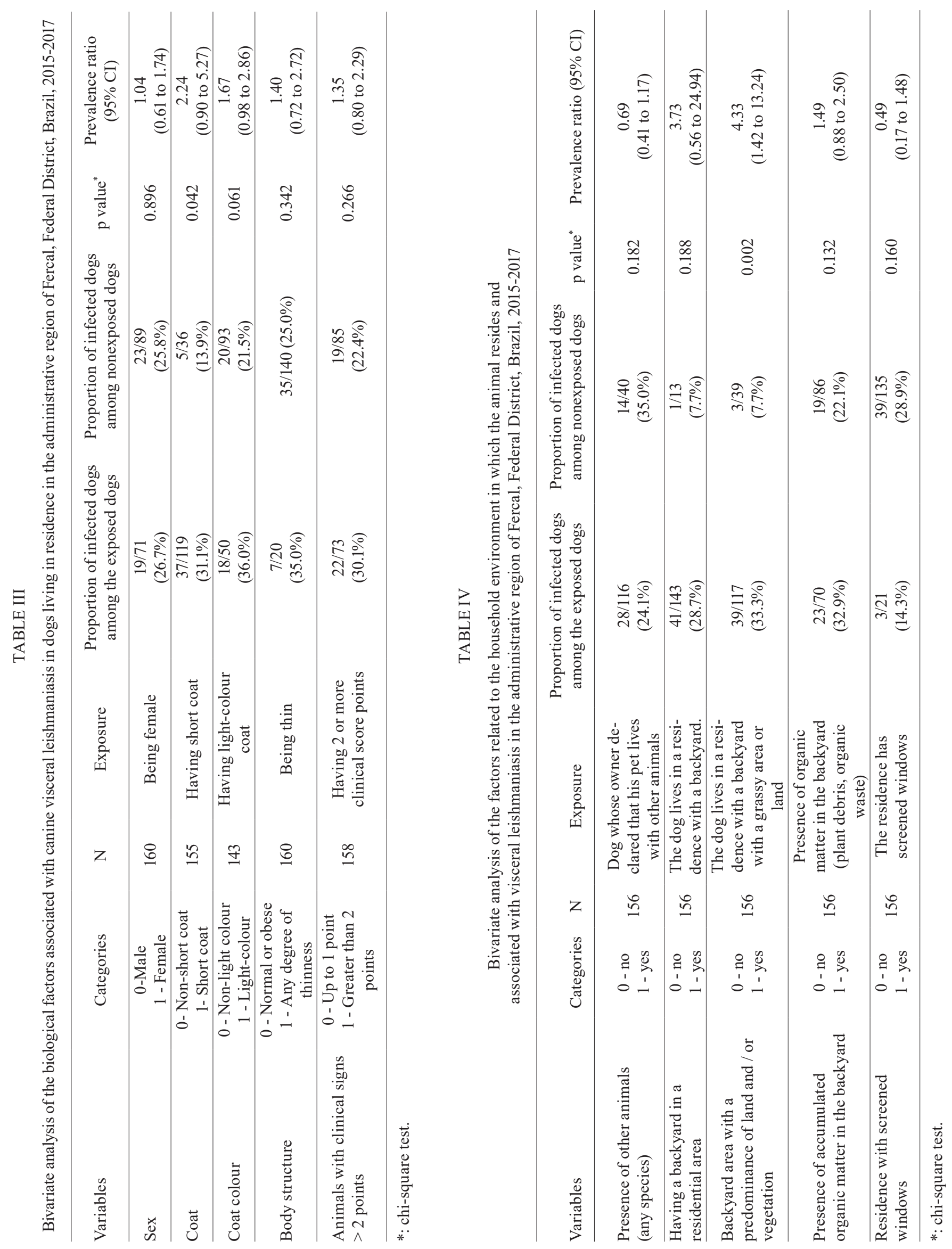


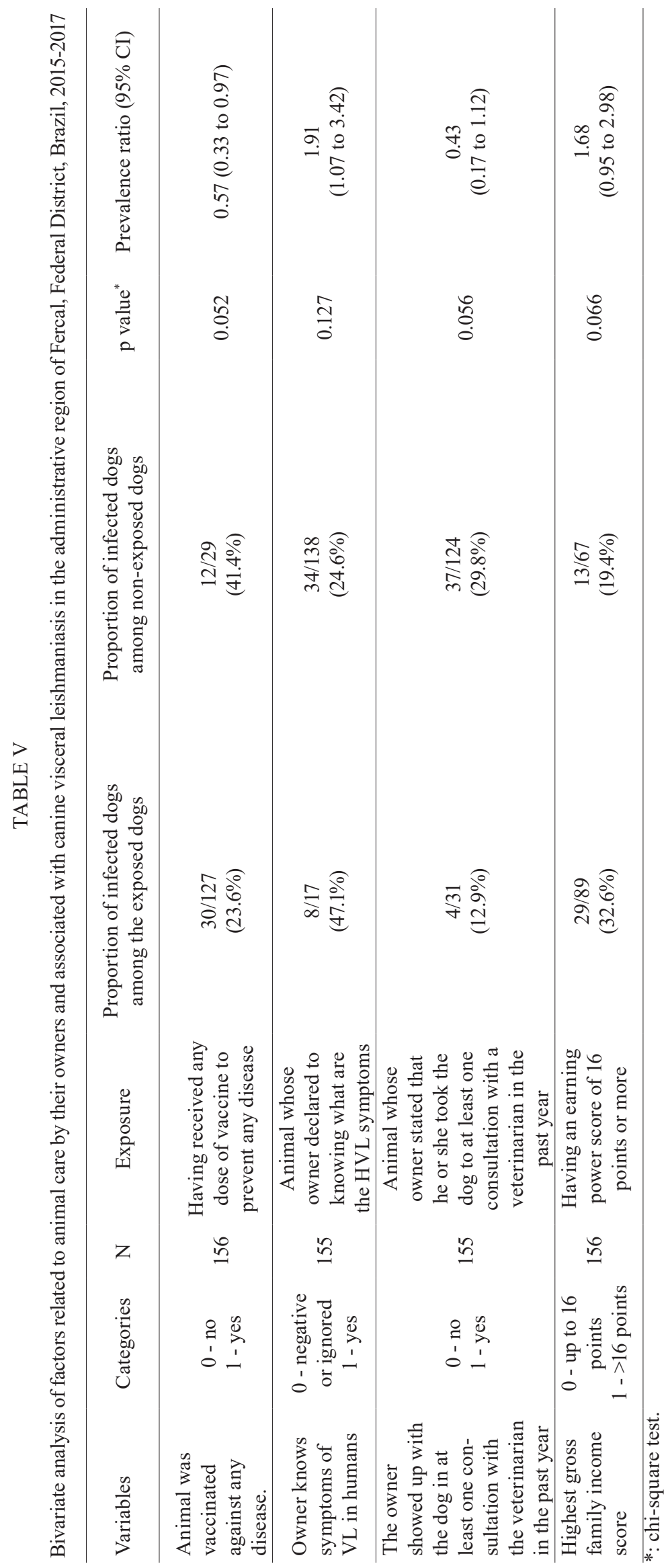


sequential RT DPP/ELISA rK39 testing was 19/160 dogs or $11.88 \%$ (95\% CI: 7.74 to 17.80$)$.

Table III shows the bivariate analysis of the biological factors possibly associated with CVL. Only two factors (short coat and light-colour coat) exhibited at least a moderate statistical association ( $p$-value $\leq 0.2$ ). Table IV provides the results of the bivariate analysis of the factors that were related to the environment in which the animal resided and were associated with CVL. All factors exhibited a moderate statistical association ( $p$-value $\leq 0.2$ ).

The results of the bivariate analysis of the exposure factors that were related to animal care performed by owners and associated with CVL revealed that all factors had a statistically significant association ( $p$-value $\leq 0.2$ ). Notably, the vaccination cards for the dogs were confirmed (Table V).

Poisson regression model was used with the exposure factors that exhibited at least a moderate statistical association in the bivariate analysis $(p \leq 0.2)$. In the model, according to Table VI, the factors associated with higher prevalence of infection were short coat, backyard area with a predominance of land and/or vegetation and highest family gross income score.

\section{DISCUSSION}

The prevalence of infection identified in the present study was higher (26.25\%; 95\% CI: 20.05 to 33.57 ) than that previously recorded in the endemic areas of the Federal District and higher than that estimated a priori during the sample calculation. In previous studies, the reported prevalence ranged from 7 to $14 \% .^{(22,29)}$ This discrepancy is most likely due to the combined use of a larger number of diagnostic techniques in the present study, especially PCR, which enabled the detection of a larger number of infected animals because of its greater sensitivity. ${ }^{(27,30)}$

The difference of $12.5 \%$ between the prevalence of infection (26.25\%; 95\% CI: 20.05 to 33.57 ) and the prevalence of the disease $(13.75 \%$; $95 \%$ CI: 9.26 to 19.94$)$ may have resulted from the greater sensitivity of the combination of diagnostic methods used for the detection of infected dogs. The detection of asymptomatic-infected dogs is important in terms of epidemiological surveillance, especially because autochthonous cases of human VL have been reported in this region..$^{(20,21)}$ Issues related to the detection of infected animals are even more concerning when assessing the seroprevalence of infection based on the combination of results from the TR DPP/ EIE-CVL tests, ${ }^{(31)}$ currently recommended by a disease control program $(9.38 \%$; $95 \%$ CI: 5.76 to 14.89$)$, which were markedly lower than the estimate obtained by combined methodologies that included molecular diagnosis. The under-detection of cases of asymptomatic canine infection caused by the lack of sensitivity of the methods recommended for routine examination has already been highlighted by other authors as a possible factor associated with the lack of effective CVL control measures currently recommended in Brazil. ${ }^{(27,32,33,34)}$

There was no significant difference between the clinical signs scores for infected and noninfected dogs, and there were dogs with suggestive symptoms that were not infected with leishmaniasis but were possibly affected 
by other diseases that were not specifically investigated in this study. This observation is consistent with the perception that the clinical syndrome associated with CVL is nonspecific. Onychogryphosis was the only clinical finding that was significantly associated with CVL. This finding is consistent with the literature, which reports that onychogryphosis is one of the clinical signs most frequently associated with dogs with VL. ${ }^{(25,35)}$

Poisson regression with robust adjustment was used to explore the relationship between exposure factors and infection outcome, and proximal and distal exposure categories were established for the development of the model. The use of this technique has been indicated in cross-sectional studies with PR because it produces an adequate fit without being affected by the magnitude of the prevalence of the event of interest. ${ }^{(36)}$

A short coat is a characteristic that has been associated with the risk of CVL in other studies, probably because short-coated dogs attract more vectors than do long-coated dogs probably because of the pattern of body heat radiation or $\mathrm{CO}_{2}$ release. ${ }^{(12)}$ The study by Coura-Vital et al. ${ }^{(13)}$ for example, identified a hazard ratio (HR) of 1.9 (95\% CI: 1.1 to 3.4), and Leal et al. ${ }^{(14)}$ estimated an OR of 1.8 (95\% CI: 1.5 to 2.1) for the association between short coat and the presence of Leishmania infection.

The association of infection with the presence of a backyard at the residence with a predominance of land and/or vegetation reinforces the idea that environmental characteristics are important in the transmission and maintenance of this disease consistently identified in other studies. ${ }^{(37,38)}$ Interestingly, environmental interventions directed to the modification of the scenario around the residences may be impractical because they could have a negative externality, such as reduced plant cover, or reduced soil drainage which creates challenges when determining interventions aimed at protecting dogs from vector bites. Thus, the use of collars with repellents has been recently investigated, with promising results. , $^{(9,11,39,40,41)}$ In turn, other interventions that improve the environment, such as the adequate collection of solid waste, ${ }^{(13,17,42)}$ which has a positive externality, should always be encouraged among the recommended measures to reduce the infection burden in the community; however, there is a lack of specific studies that determine the magnitude of its potential impact on the transmission of CVL.

Although HVL has been traditionally associated with poverty, ${ }^{(2)}$ in the present study, there was a significant association between higher family gross income of owners and the possibility of having CVL. This is an association that had not been previously described in the literature. The family gross income score distribution in sample of owners included in the study demonstrated that most of them belonging to socioeconomic class $\mathrm{C} 1$ or lower [Supplementary data (Fig. 2)] and the exploration of risk by quartiles show a cut-off for increased risk around the score level between B2 and C1 classes. Then, the external validity of our results related to tutors' income level would be limited to populations with similar income distribution. The hypotheses that would explain this association may be related to the fact that owners with better socioeconomic status provide better care to animals, which would result in a higher probability of survival in relation to other lethal and vaccine-preventable conditions (e.g., distemper virus and parvovirus); ${ }^{(43)}$ as seen, the symptomatic dogs were from owners with a lower income and the asymptomatic dogs were from a bigger income. Additionally, when the animal ages, these diseases could trigger some immunodeficiency. Therefore, increased survival time increases the exposure risk of VL infection as well as the susceptibility of the animal. Furthermore, better nutrition could keep the dog healthier, and even if infected by leishmaniasis, the dog would survive longer. This association can be very challenging in the current framework of recommendations, which include the euthanasia of infected dogs, as owners with better income may be those that most often refuse euthanasia. ${ }^{(44)}$ This lack of euthanasia allows dogs to remain in the environment as sources of the disease to other dogs and to the human population. The present observation related to the socioeconomic status of the owners contributes to raising new hypotheses to explain the lack of effectiveness of current control models that have failed to prevent the territorial dispersion of the disease.

In epidemiological terms, the role of asymptomatic dogs as a source of infection may be even more important than the role of the population of sick dogs, which are at a lower proportion, a fact that has been addressed in other studies. ${ }^{(45,46)}$ Although asymptomatic dogs transmit Leishmania spp. at a lower rate than do symptomatic dogs, ${ }^{(32,47)}$ they may represent a numerically larger group of animals serving as source of infection. Moreover, symptomatic dogs that traditionally undergo interventions, whether euthanasia or treatment, constitutes a smaller portion of the population, as demonstrated in this study.

The use of the owner's income score as an exposure factor opens a debate for future studies on the role of owners in the process of CVL prevention; until now, there has been an almost exclusive focus on the actions of epidemiological surveillance teams dedicated to the management of zoonoses. The success of new prophylactic interventions, such as the use of insecticide-impregnated dog collars, oral repellents or even vaccines, will certainly depend on the participation of owners to ensure the appropriate use and timely replacement of collars or the administration of other drugs and vaccines, which can have a direct or indirect relationship with the socioeconomic status of the owners, influencing the effectiveness of the interventions.

This study has limitations inherent to a cross-sectional approach, such as the inability to ascertain causality. The limitation imposed by the absence of laboratory tests complementary to the clinical data should also be considered, which could have helped in the identification of some effects of infection on kidney function, haematological conditions and the nutritional status of apparently healthy animals. The possibility of observation bias should also be considered, as several observers evaluated and recorded the clinical conditions of the studied animals and applied the questionnaires. In this sense, efforts were made to minimise the observation bias in the clinical evaluation, such as the execution of a previous pilot project, ${ }^{(27)}$ as well as masking of the clinical data to per- 
form diagnostic techniques. The generalisation of these results is something to be viewed with precaution due to the type of study that was conducted. However, the explanatory hypotheses for the results deserve attention and should be the object of further cohort research.

In addition to the aforementioned limitations, the possibility of survival bias should be considered when understanding the significance of the highest income score associated with a higher prevalence of CVL. That is, all the hypotheses discussed here may have been affected by a higher probability of survival when a dog has a guardian with higher income. This does not diminish the importance that asymptomatic dogs could have in the maintenance of VL in a community. Therefore, future studies should be methodologically careful when making this distinction. Finally, we estimated dog population size corresponding to $4 \%$ of the human population. Actually, that number is lower than the usual dog to human ratio reported in the literature from other localities in Brazil and other countries. In 2019, the public health authorities in the Federal District estimate dog population equivalent to $12 \%$ of the human population for rabies vaccination purposes. ${ }^{(48)}$ Besides the number of dogs in the studied region, the actual number of dogs recruited in our study resulted in acceptable precision of the prevalence rates and PR estimates.

In conclusion - The present study identified three relevant factors associated with Leishmania infection in a predominantly asymptomatic canine population, standing out as the first study to associate owners' higher socioeconomic status with the highest prevalence of infection.

\section{ACKNOWLEDGEMENTS}

To the veterinarian Laurício Monteiro Cruz, the biologist Antonio Fonseca da Cunha Neto, and the entire team of the Environmental Surveillance Board of the Federal District for the implementation of the RT-DPP and ELISA tests. We also thank Ana Paula Sampaio Cardoso and Ana Claudia Negret Scalia for conducting the PCR analysis and for technical assistance in the laboratory, and the students Gabriela Sousa and Letícia Araujo for their dedication to this study. We also thank The Clinical Research and Public Policies on Infectious and Parasitic Diseases, René-Rachou Research Centre-FIOCRUZ of Belo Horizonte, Minas Gerais, Brazil, for performing the rK39 ELISA test.

\section{AUTHORS' CONTRIBUTION}

GASR and AIPT provided an intellectual framework for the preparation of this study; AIPT and DMS collected the biological samples, conducted the PCR, culture, and parasitology experiments; LRS lead the Poisson Regressions analyses. All authors contributed to data analysis and drafting the manuscript, and all have read and approved the final version. The authors have no conflicts of interest to declare.

\section{REFERENCES}

1. Lainson R. The Neotropical Leishmania species: a brief historical review of their discovery, ecology and taxonomy. Rev Pan-Amaz Saude. 2010; 1(2): 13-32.

2. Alvar J, Vélez ID, Bern C, Herrero M, Desjeux P, Cano J, et al. Leishmaniasis worldwide and global estimates of its incidence. PLoS One. 2012; 7(5): e35671.
3. Bezerra JMT, Araújo VEM, Barbosa DS, Martins-Melo FR, Werneck GL, Carneiro M. Burden of leishmaniasis in Brazil and federated units, 1990-2016: findings from global burden of disease study 2016. PLoS Negl Trop Dis. 2018; 12(9): e0006697.

4. Carvalho IS, Peixoto HM, Romero GAS, Oliveira MRF. Cost of visceral leishmaniasis care in Brazil. Trop Med Int Health. 2017; 22(10): 1579-89.

5. Rocha ICM, Santos LHM, Coura-Vital W, Cunha GMR, Magalhães FC, Morais M, et al. Effectiveness of the Brazilian visceral leishmaniasis surveillance and control programme in reducing the prevalence and incidence of Leishmania infantum infection. Parasit Vectors. 2018; 11(1): 586.

6. MS - Ministério da Saúde. Secretaria de Vigilância em Saúde. Departamento de Vigilância Epidemiológica. Manual de vigilância e controle da leishmaniose visceral. Brasília: Editora do Ministério da Saúde; 2014. 120 p. (Série A. Normas e Manuais Técnicos). Available from: http://bvsms.saude.gov.br/bvs/publicacoes/manual_vigilancia_controle_leishmaniose_visceral_ledicao.pdf.

7. Akhoundi M, Kuhls K, Cannet A, Votýpka J, Marty P, Delaunay $\mathrm{P}$, et al. A historical overview of the classification, evolution, and dispersion of Leishmania parasites and sandflies. PLoS Negl Trop Dis. 2016; 10(3): e0004349.

8. Werneck GL. Visceral leishmaniasis in Brazil: rationale and concerns related to reservoir control. Rev Saude Publica. 2014; 48(5): 851-6.

9. Silva RA, Andrade AJ, Quint BB, Raffoul GES, Werneck GL, Rangel EF, et al. Effectiveness of dog collars impregnated with $4 \%$ deltamethrin in controlling visceral leishmaniasis in Lutzomyia longipalpis (Diptera: Psychodidade: Phlebotominae) populations. Mem Inst Oswaldo Cruz. 2018; 113(5): e170377.

10. dos Santos-Nogueira F, Avino VC, Galvis-Ovallos F, Pereira-Chioccola VL, Moreira MAB, Romariz APPL, et al. Use of miltefosine to treat canine visceral leishmaniasis caused by Leishmania infantum in Brazil. Parasit Vectors. 2019: 12(1): 79.

11. Coura-Vital W, Leal GGA, Marques LA, Pinheiro AC, Carneiro $\mathrm{M}$, Reis AB. Effectiveness of deltamethrin-impregnated dog collars on the incidence of canine infection by Leishmania infantum: a large scale intervention study in an endemic area. PLoS One. 2018; 13(12): e0208613.

12. Belo VS, Struchiner CJ, Werneck GL, Barbosa DS, de Oliveira $\mathrm{RB}$, Neto RG, et al. A systematic review and meta-analysis of the factors associated with Leishmania infantum infection in dogs in Brazil. Vet Parasitol. 2013; 195(1-2): 1-13.

13. Coura-Vital W, Reis AB, Fausto MA, Leal GGA, Marques MJ, Veloso VM, et al. Risk factors for seroconversion by Leishmania infantum in a cohort of dogs from an endemic area of Brazil. PLoS One. 2013; 8(8): e71833.

14. Leal GGA, Carneiro M, Pinheiro AC, Marques LA, Ker HG, Reis AB. Risk profile for Leishmania infection in dogs coming from an area of visceral leishmaniasis reemergence. Prev Vet Med. 2018; 150: $1-7$.

15. Costa KF, Amóra SS, Couto CF, Souza CS, Silva LF, d'Escoffier $\mathrm{LN}$, et al. Awareness of visceral leishmaniasis and its relationship to canine infection in riverside endemic areas in northeastern Brazil. Rev Soc Bras Med Trop. 2014; 47(5): 607-12.

16. de Castro JM, Rodrigues SM, Tarso S, Costa FL, Rodrigues ACCP, Vieira LDF, et al. Conhecimentos, percepções de indivíduos em relação à leishmaniose visceral humana como novas ferramentas de controle. Ensaios Cienc Biol Agr Saude. 2016; 20(2): 93-103.

17. Ursine RL, Dias JVL, Morais HA, Pires HHR. Human and canine visceral leishmaniasis in an emerging focus in Araçuaí, Minas Gerais: spatial distribution and socio-environmental factors. Mem Inst Oswaldo Cruz. 2016; 111(8): 505-11. 
18. Constantino C, Pasquali AKS, Caldart ET, Ferreira FP, Marana ERM, Freire RL, et al. Seroepidemiology of Leishmania spp. in dogs residing in Telêmaco Borba, Paraná, Brazil. Semin Cienc Agrar. 2014; 35(6): 3181-90.

19. Sevá AP, Mao L, Galvis-Ovallos F, Lima JMT, Valle D. Risk analysis and prediction of visceral leishmaniasis dispersion in São Paulo State, Brazil. PLoS Negl Trop Dis. 2017; 11(2): e0005353.

20. Carranza-Tamayo CO, Carvalho MS, Bredt A, Bofil MI, Rodrigues RM, Silva AD, et al. Autochthonous visceral leishmaniasis in Brasilia, Federal District, Brazil. Rev Soc Bras Med Trop. 2010; 43(4): 396-9.

21. Carranza-Tamayo CO, Werneck GL, Romero GAS. Are opossums a relevant factor associated with asymptomatic Leishmania infection in the outskirts of the largest Brazilian cities? Braz J Infect Dis. 2016; 20(2): 119-26.

22. Secretaria de Saúde do Distrito Federal. Informativo ambiental das leishmanioses no DF. Brasília. 2013. Available from: http:// www.saude.df.gov.br/images/Informativos/DIVAL/Informativo Ambiental 2013 Leishmanioses EM PDF.pdf. Accessed in March 8, 2014 .

23. Raggio LR, MagnaninI MMF. A lógica da determinação do tamanho da amostra em investigações epidemiológicas. Cad Saude Coletiva. 2000; 8(2): 9-28

24. ABEP. Alterações na aplicação do Critério Brasil. São Paulo: Associação Brasileira de Empresas de Pesquisa. 2012. http://www. abep.org/Servicos/Download. aspx?id=03.

25. Solano-Gallego L, Miró G, Koutinas A, Cardoso L, Pennisi MG, Ferrer L, et al. LeishVet guidelines for the practical management of canine leishmaniosis. Parasit Vectors. 2011; 4: 86

26. Proverbio D, Spada E, de Giorgi GB, Perego R, Valena E. Relationship between Leishmania IFAT titer and clinicopathological manifestations (clinical score) in dogs. Biomed Res Int. 2014; 2014: 412808.

27. Teixeira AIP, Silva DM, Vital T, Nitz N, de Carvalho BC, Hecht $\mathrm{M}$, et al. Improving the reference standard for the diagnosis of canine visceral leishmaniasis: a challenge for current and future tests. Mem Inst Oswaldo Cruz. 2019; 114: e180452.

28. Governo Federal. Brasil. Lei 11794 de 8 de outubro de 2008. 2008. Available from: http://www.planalto.gov.br/ccivil_03/_ato20072010/2008/lei/111794.htm.

29. Silva GJ, Silva ET, Costa GRT, Santos IB. Vigilância da leishmaniose visceral no Distrito Federal: aspectos organizacionais, situação epidemiológica e medidas intersetoriais. Com Cienc Saude. 2017; 28(2): 149-57.

30. Lopes EG, Geraldo-Junior CA, Marcili A, Silva RD, Keid LB, Oliveira TM, et al. Performance of conventional PCRs based on primers directed to nuclear and mitochondrial genes for the detection and identification of Leishmania spp. Rev Inst Med Trop São Paulo. 2016; 58: 41

31. MS/SVS/DVIT - Ministério da Saúde/Secretaria de Vigilância em Saúde/Departamento de Vigilância de Doenças Transmissíveis. Nota Técnica Conjunta 01/2011. Brasília: CGDT/CGLAB/DVIT/ SVS/MS; 2011

32. Laurenti MD, Rossi CN, da Matta VL, Tomokane TY, Corbett CEP, Secundino NFC, et al. Asymptomatic dogs are highly competent to transmit Leishmania (Leishmania) infantum chagasi to the natural vector. Vet Parasitol. 2013; 196(3-4): 296-300.

33. Lopes EG, Sevá AP, Ferreira F, Nunes CM, Keid LB. Serological and molecular diagnostic tests for canine visceral leishmaniasis in Brazilian endemic area: one out of five seronegative dogs are infected. Epidemiol Infect. 2017; 145(12): 2436-44.

34. Borja LS, Sousa OMF, Solcà MS, Bastos LA, Bordoni M, Magalhães JT, et al. Parasite load in the blood and skin of dogs naturally infected by Leishmania infantum is correlated with their capacity to infect sand fly vectors. Vet Parasitol. 2016; 229: 110-7.

35. Gouvêa MV, Mendonça IV, Cruz MSP, Costa CHN, Braga JU, Werneck GL. Predictive factors for Leishmania infantum infection in dogs examined at a veterinary teaching hospital in Teresina, State of Piauí, Brazil. Rev Soc Bras Med Trop. 2016; 49(1): 107-11.

36. Barros AJ, Hirakata VN. Alternatives for logistic regression in crosssectional studies: an empirical comparison of models that directly estimate the prevalence ratio. BMC Med Res Methodol. 2003; 3: 21

37. Figueiredo ABF, Werneck GL, Cruz MSP, Silva JP, Almeida AS. Uso e cobertura do solo e prevalência de leishmaniose visceral canina em Teresina, Piauí, Brasil: uma abordagem utilizando sensoriamento remoto orbital. Cad Saude Publica. 2017; 33(10): 1-13.

38. Abrantes TR, Werneck GL, de Almeida AS, Figueiredo FB. Environmental factors associated with canine visceral leishmaniasis in an area with recent introduction of the disease in the State of Rio de Janeiro, Brazil. Cad Saude Publica. 2018; 34(1): e00021117.

39. Alves EB, Figueiredo FB, Werneck GL. Dificuldades operacionais no uso de coleiras caninas impregnadas com inseticida para o controle da leishmaniose visceral, Montes Claros, MG, 2012. Epidemiol Serv Saude. 2018; 27(4): e2017469.

40. Lopes EG, Sevá AP, Ferreira F, Nunes CM, Keid LB, Hiramoto $\mathrm{RM}$, et al. Vaccine effectiveness and use of collar impregnated with insecticide for reducing incidence of Leishmania infection in dogs in an endemic region for visceral leishmaniasis, in Brazil. Epidemiol Infect. 2018; 146(3): 401-6.

41. Kazimoto TA, Amora SSA, Figueiredo FB, Magalhães JM, Freitas YABN, Sousa MLR, et al. Impact of $4 \%$ deltamethrin-impregnated dog collars on the prevalence and incidence of canine visceral leishmaniasis. Vector Borne Zoonotic Dis. 2018; 18(7): 356-363.

42. da Silva JP, Werneck GL, Macedo EC, de Carvalho H, Cruz MS. Factors associated with Leishmania chagasi infection in domestic dogs from Teresina, State of Piauí, Brazil. Rev Soc Bras Med Trop. 2012; 45(4): 480-4

43. Day MJ, Horzinek MC, Schultz RD, Squires RA. WSAVA guidelines for vaccination of dogs and cats. J Small Anim Pract. 2016; 57(1): 4-8.

44.Zuben APB, Donalísio MR. Difficulties in implementing the guidelines of the Brazilian visceral leishmaniasis control program in large cities. Cad Saude Publica. 2016; 32 (6): e00087415.

45. Esteva L, Vargas C, Vargas-de-León C. The role of asymptomatics and dogs on leishmaniasis propagation. Math Biosci. 2017; 293: $46-55$

46. Zou L, Chen J, Ruan S. Modeling and analyzing the transmission dynamics of visceral leishmaniasis. Math Biosci Eng. 2017; 14(5): 1585-604.

47. Courtenay O, Carson C, Calvo-Bado L, Garcez LM, Quinnell RJ. Heterogeneities in Leishmania infantum infection: using skin parasite burdens to identify highly infectious dogs. PLoS Negl Trop Dis. 2014; 8(1): e2583.

48. Governo do Distrito Federal. Projeto da XLI campanha de vacinação antirrábica de cães e gatos do Distrito Federal/2019. 2019. Available from: http://www.sia.df.gov.br/wp-conteudo/uploads/2019/07/PROJETO_CAMPANHA_ANTIRRABICA_DE_ CAES E GATOS 2019.pdf. 